\title{
"Neuronas", el libro que no llegó a escribir Valdelomar
}

\author{
por \\ Estuardo Núñe\%
}

Desde el año anterior a su inesperada y absurda muerte, Abraham Valdelomar anunciaba a sus amigos y lectores que estaba escribiendo un libro titulado Neuronas, con el que proyectaba promover una nueva modalidad literaria (*).

Cuando la muerte ocurrió, los devotos familiares sólo encontraron unas pocas cuartillas con ese título y que contenian, además de un breve prólogo, algunos pensamientos irónicos, que parcialmente fucron después publicados en la revista Studium, (Lima, enero 1920).

En efecto, aquel plan de un nuevo libro quedó truncado por el prematuro deceso. No fue una realidad sino un proyecto, del cual se conserva un muestrario que nos permite, no obstante, imaginar lo que hubiera sido terminado.

Entre los papeles ineditos de Valdelomar he logrado hallar algunas "neuronas" que no figuran en la publicación de Studium, de tal manera que a los pensamientos publicados en dicha revista, pueden agregarse como totalmente desconocidos algunas decenas más, con lo que se integra todo lo escrito por el autor con destino a este proyecto de libro.

Para ese esbozo de libro se escribieron unos pocos pensamientos que el propio Valdelomar calificaba de "procesos imaginativos a base de lógica".

Publicamos en este número el texto completo de aquellas "neuronas" escritas por Valdelomar, en los últimos meses de su vida (entre 1918 y 1919).

La crítica ha señalado con insistencia las "greguerías" del

(*) La más lejana referencia a este libro en preparación se encuentra en un reportaje hecho a Valdelomar en La Reforma de Trujillo, mayo de 1918, dionde habla de "Neuronas, libro de filosofia, en prensa". 
escritor español Ramón Gómez de la Serna, como antecedente de las "neuronas" del peruano. Jorge Basadre señaló la influencia por primera vez:

"Las pequeñas frases inconexas y agudas que él llamó "neuronas" le dan también parecido con las greguerias".

(Equivocaciones, Lima, 1928, p. 45).

Lo siguió más explícitamente José Carlos Mariátegui en estos párrafos:

"La "greguería" - dice Mariátegui- empieza con Valdelomar en nuestra literatura. Me consta que los primeros libros de Gómez de la Serna que arribaron a Lima, gustaron sobremanera a Valdelomar. El gusto atomístico de la "greguería" era, además, innato en él, aficionado a la pesquisa original y a la búsqueda microcósmica. Pero, en cambio, Valdelomar no sospechaba aún en Gómez de la Serna el descubridor del Alba. Su retina de criollo impresionista era experta en gozar voluptuosamente, desde la ribera dorada, los colores ambiguos del crepúsculo... Impresionismo, esto es, dentro de su variedad espacial, la filiación más precisa de su arte".

\section{(7 Ensayos..., Lima, 1929, p. 216).}

Finalmente, Luis Fabio Xammar apunta más tarde y analiza más a fondo la estructura de la "neurona":

"Tres elementos integran la sintesis que da por resultado las "neuronas"? Ufilosofía i deolia/ realidad, cerebralismo en el estilo y acento humorístico en la expresión. Las "neuronas" tienen en ocasiones una mayor importancia que las "greguerias" de Gómez de la Serna - sus gemelas- por el acervo de crítica que llevan en sí. El ingenio es parte principal, pero no lo es todo. Existe invivita en ella, un deseo más trascendental: buscan lograr caricaturas de nuestra realidad: instantáneas, en las que debajo de la frase simpática y despreocupada, se sienta el zarpazo de la verdad. Por esta razón es que la filosofía un tanto escéptica y derrotada de Valdelomar, la tenemos que catear a través de estas "neuronas" impregnadas de un júbilo doloroso".

$$
\text { (Valdelomar, signo, Lima, 1940, p. 71) }
$$

Como es de verse, Xammar se aleja un tanto de las definiciones anteriores, esbozando una reserva a la idea de de identificar "greguerías" con "neuronas". 
Podemos acudir a una apreciación paralela, a fin de darnos cuenta de la diferencia esencial entre ambas. Observemos estas "greguerías":

"Yo no sé cuál será peor: si la mosca del sucño o la mos. ca que no tiene sueño".

"La jirafa es un caballo alargado por la curiosidad".

"Las chuletas son los fuegos fatuos del hambre".

Y luego estas "neuronas":

"Los patos ticne un aspecto de hombres de negocios: gordos, improvisados y de malos antecedentes".

"El submarino es una especie de corvina grande con artilleria. En cambio la corvina no tiene artillería pero nunca se va a pique".

"Hay mujeres que deberían tener nombres de calles. Esta se llamaría «Espalda de Santa Clara»".

La diferencia es esencial y salvo en la breve apariencia material, no cabe posibilidad de considerarlas "gemelas" Gómez de la Serna juega ingeniosamente con el mero contenido semántico de las palabras, en tanto que Valdelomar ahonda con la ironía en la observación humana y cala más hondo en los sentimientos. Gómez de la Serna hace sutilezas celebrales, en tanto que Valdelomar se sumerje en el mundo de la sensibilidad.

En sus neuronas, Valdelomar está en realidad más cerca de Oscar Wilde que de Gómez de la Serna. Mientras éste último hace sólo juego de ingenio o de palabras, en Wilde como en ValdelomargeP pensamientoleseincisivo y crítico, con cierta intención de sátira social. Según la propia fórmula de Gómez de la Serna - dada en 1910 - la greguería sólo era una combinación de humorismo más metáfora, y explícitamente:

"Un cambio de perspectiva al mirar las cosas, una inclusión de cllas en un nuevo contexto, un obligarlas a asumir una función que de por sí no tienen, y ese choque con lo otro hace que brote una especial iluminación sobre ellas; esto es propio de toda metáfora; pero la greguería añade a su propósito lírico una envoltura humorística o irónica; es decir, no se entrega ingenuamente a la metáfora, sino que la pone entre paréntesis, la amanera un poco, como advirtiendo: "esto es una metáfora»".

Por su parte Valdelomar definía su "neurona" como:

"Cierto linaje de micro-organismos a manera de diminu- 
tos pulpos o estrellas de radios vibrátiles... un arduo proceso imaginativo o base de lógica... y breves comprimidos de verdad..."

Habría que lamentar únicamente que las Neuronas de Valdelomar constituyeron sólo un proyecto de libro, para el que llegó a pergeñar algunas páginas sueltas. Entre sus papeles inéditos existentes en la Biblioteca Nacional sólo se encuentran unos pocos pensamientos que agregan apenas un pequeño aporte a lo que fue publicado por la revista Studium después de su muerte.

Quedó sólo en plan ese libro que anunciaba Valdelomar a sus amigos, poco antes de su inesperado deceso, y con el que proyectaba abrir una nueva faceta de su personalidad literaria.

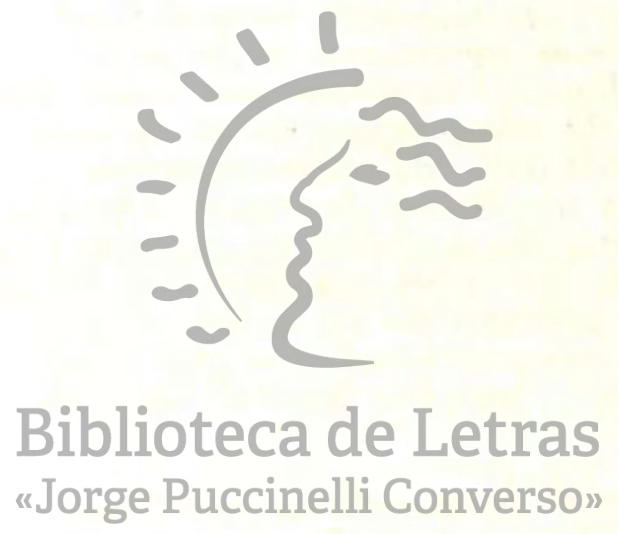

